\title{
AN INFORMATION SECURITY CURRICULUM IN FINLAND
}

\author{
Teemupekka Virtanen, Ronja Addams-Moring \\ Telecommunication Software and Multimedia Laboratory \\ Helsinki University of Technology \\ P.O. Box 5400, FIN-02015 HUT \\ teemupekka.virtanen@hut.fi, ronja.addams-moring@hut.fi
}

\begin{abstract}
For several years there has been a de facto curriculum of information security at Helsinki University of Technology. Officially this curriculum has been a part of the telecommunication software major, but now there is a need for an own major for information security. One version of this major is a master's program for international students. This program already exists and some of our courses have to be developed to fit its needs. Another international aspect is the ERASMUS program [katsikas] we are joining.

During this process we have designed new curricula consisting of a major and a minor for information security. The major is intended for developers (computer professionals) and the minor for administrators.
\end{abstract}

Key words: Information security, curriculum, university, ERASMUS

\section{BACKGROUND}

\subsection{Structure of University Studies in Finland}

The main degree at the university level in Finland is a master's degree. At some universities it is possible to get an intermediate bachelor's degree but most students continue direct to a master's degree. There are several lower level institutes for bachelor's degrees. 
The measuring system for studies in Finland is a credit point (cr). One credit point means 40 hours of work. A master's degree is 160 or $180 \mathrm{cr}$. A bachelor's degree is $120 \mathrm{cr}$. In theory one can get a master's degree in 4.5 years but in practise it takes around six years. [virtanen2]

At Helsinki University of Technology [hut] students are accepted into curricula, which are typically one per department. In a curriculum there are basic scientific studies, advanced studies, a major and one or two minors. In this paper we use the term curriculum to refer to what actually is a major and a minor in the Department of Computer Science and Engineering [tik].

\subsection{Current Courses at HUT}

Information security has been a de facto choice for students for several years. There have been several courses in the area of information security in the Telecommunication Software and Multimedia Laboratory [tml] in the Department of Computer Science and Engineering. It has been possible to select these courses as a part of the communication software major and thus, unofficially, have an information security major. However, there has been no official major of information security.

Most of the majors at HUT are restricted for the department's own students. Mainly students in the Department of Computer Science and Engineering can select communication software as their major. They all have a strong background in computers and programming. The courses in the major can thus have programming assignments and laboratory work.

The communication software major is $24 \mathrm{cr}$. There are $14 \mathrm{cr}$ of mandatory courses and $10 \mathrm{cr}$ of freely selectable courses. The mandatory courses are the same for all students in the major. These courses are

- Computer networks, 3cr [T-110.350]

- Laboratory work on telecommunication software, 3cr [T-110.400]

- Individual project (a software project done in a group), 5cr [T-76.115]

- Seminar on network security, 3cr [T-110.501] or seminar on internetworking, 3cr [T-110.531]

The freely selectable courses come from a long list of courses. This selection makes the difference between information security and other topics in the communication software major. Recommended courses for information security are

- Basics of data security, 2-3cr [T-110.401]

- Special course in practical security of information systems, $3 \mathrm{cr}$ [T-110.452]

- Developing process for information security, 3cr [T-110.454] 
- Foundation of cryptology, 3cr [T-110.503]

- Seminar on corporate security, 3cr [T-110.554]

There are also four courses, which have different topics each year. Of these any number from one to four can be arranged during a university year. In the fall term 2000 the topic was Seminar on Computer Security, 3cr [T-110.447].

It is also possible to include some courses from other laboratories in the major. These courses are accepted individually by the professor. Some examples of these courses are

- Cryptography and data security, 3cr [T-79.159]

- Safety critical systems, 2cr [T-79.232]

- Usability evaluation, 4cr [T-121.600]

\subsection{Problems}

There are currently three main problems: the lack of a major, the concentration on network security in existing courses and therefore the rather demanding technical prerequisites.

There is no major for information security. It is difficult to design a curriculum without a "brand". In the past there has been one professor for several areas of interest and he has been able to manage courses in several areas. Now there is a professor dedicated to information security. Therefore it is more important to find those students who will actually concentrate on information security. We could suggest a good combination of courses or define an information security "thread" but in both cases there would be many students who have a rather haphazard mixture of courses from different areas of the communication software major. Such students would likely fail to develop a deeper understanding of any area of communication software, information security included.

Many of the courses are in the network security area. Participating in these courses requires a good knowledge of computers and communication. However, information security is a very interesting topic for many of the students of the other departments. Designing courses for students with very heterogeneous backgrounds is difficult at best and sometimes impossible to do well.

Clearly, we should arrange courses on general security topics. These courses should not require special knowledge in computing. According to many of the models in information security there are several non-computer topics in the information security, too [virtanen]. The need for understanding corporate security is stated also in [schou]. 
In the information security area there are also several technical topics we currently lack. Among these areas are e.g. database security, malware and security certification.

\section{THE NEW CURRICULUM}

\subsection{The Major in Information Security Technologies}

This major is designed for students in the Department of Computer Science and Engineering. Good knowledge in computers and programming are required as prerequisite.

The "product" of this major is a designer of information security products. After graduation these students may work in companies manufacturing these products. There are also several consulting companies in this area. Security components are an important part of many other products and there is a need of specialists in more general software and hardware companies as well. Furthermore, most companies have communication systems and need information security specialists to design their networks in a secure way.

There will be a new course, which is a mandatory prerequisite for this major

- Basics of corporate security, a new course which is actually the same as the general part of current basics of data security course.

Organizing security in an company, terms and threat management

The information security technologies major is $24 \mathrm{cr}$. There are approximately $12 \mathrm{cr}$ of mandatory courses and approximately $12 \mathrm{cr}$ of freely selectable courses. The mandatory courses are the same for all students in the major. To begin with, these courses are mostly the same as in the old major:

- Computer networks, 3cr [T-110.350]

- Laboratory work on telecommunication software, 3cr [T-110.400]

- Information security technology, a new course, which gives an overview of different technologies in the information security area. This is the technological part of the current Basics of data security course

- Individual project, 5cr [T-76.115]

- Seminar on network security, 3cr [T-110.501] or seminar on internetworking, $3 \mathrm{cr}$ [T-110.531] 
In the laboratory works we are going towards more information security related topics and probably an own course in the future.

The optional courses are

- Foundation of cryptology, 3cr [T-110.503]

- Special course in practical security of information systems, $3 \mathrm{cr}$ [T-110.452]

- Malware technologies, a new course. Technologies used in Trojan horses, viruses, worms and other malware

- Database security, a new course about designing and administrating databases in a secure way

- Security evaluation, a new course about evaluating the security level of various products including operating systems

- The four special courses with varying topics.

- Some courses from other laboratories: cryptography, critical systems, usability and product development

It is also possible to include courses from the new security administration minor to this major.

There will be a prototype version of the security evaluation course in the spring term 2002 as a special course. In the fall term 2002 the first information security technology course will be held, instead of the current basics of data security course. At the same time the malware course will be tested as a special course.

\subsection{The Minor in Security Administration}

This minor is intended for all students of Helsinki University of Technology. There are no prerequisites in computer science.

The main "product" of this minor is a security or an information security manager of an organization. After graduation these students may find a job almost anywhere as the need of these managers has increased rapidly.

The security administration minor is $20 \mathrm{cr}$. There are approximately $9 \mathrm{cr}$ of mandatory courses and approximately $11 \mathrm{cr}$ of freely selectable courses

The mandatory courses are

- Basics of corporate security, a new course which is actually the same as the general part of current basics of data security course.

Organizing security in an company, terms and threat management

- Developing process for information security, 3cr [T-110.454]

- Seminar on corporate security, 3cr [T-110.554]

The optional courses are 
- Physical and personnel security, a new course about the classical aspects of security

- The four special courses with varying topics.

- Some courses from other laboratories: business management, leadership and quality management

It is also possible to include courses from the information security technologies major to this minor.

There will be a prototype version of the physical and personnel security course in the spring term 2002 as a special course. In the spring term 2003 the first corporation security course will be held.

\subsection{The Master's Program}

For some years now there has been a master's program for people who already have a bachelor's degree. These students are typically foreigners who have earned their bachelor's degrees abroad. This program is arranged together with the Department of Electrical and Communications Engineering [master]. There are three majors in this program in the area of communication, one of which is communication software handled by our laboratory. Thus far most of the students in this program, who have selected communication software as their major, have studied other courses than information security but we have now decided to offer only the information security technologies major in the future.

Since this is an international program one must be able to pass all courses in English. This means that at least all the material must be in English, assignments and exams must be given also in English and there must be some tutoring available in English.

There is one principal and one practical reason why not all teaching can be in English. Firstly, as a Finnish university one of our duties is to spread information about information security in the Finnish society. Therefore we have to create, maintain and teach Finnish vocabulary of information security. Secondly, some visiting lecturers who are experts in special areas of security are not willing to hold their lectures in English.

The first term is common for all the students in the program. Therefore the courses are not concentrated on communication software but on communication in general. The courses in this term are

- Modulation and coding methods, 2cr [S-72.144]

- Telecommunications architectures, 4cr [T-110.300]

- Introduction to software engineering, 3cr [T-76.601]

- Parallel and distributed systems, 3cr [T-79.179] 
- Signal processing systems, 2cr [T-61.140]

The second and third terms in the information security technologies major will consist of most courses of the general information security technologies major (chapter 2.1) and some programming courses. These courses can be passed in English.

The fourth term is reserved for the master's thesis.

\section{FUTURE WORK}

There are still many topics in the security field, which are not covered in our current or planned courses. However, there is a limit to how many new courses we can implement in the near future. The new course candidates will be tested using the special courses as prototype. In the future we hope to cover most the areas of information security [katsikas2].

We have a master's program for students coming from abroad. It is possible to participate in most of our courses in English already. This means that all the material is in English, the assignments and exams are possible to answer in English and there is some tutoring available in English. Most of the lectures are still in Finnish. We will have to monitor the content of this program and the amount of lectures given in English.

Considering international co-operation, we have already decided to join the ERASMUS program. We will try to develop our courses toward distant learning and also welcome such courses from other universities. Locally, we use a computerized system for examinations. It would be possible to use this system for distant examinations also. We can offer this system for use if we arrange courses together with other universities.

\section{CONCLUSIONS}

We started teaching information security with some individual courses within the telecommunication software major at Helsinki University of Technology. Now the development has reached a state where we have the possibility to create a new major.

At the same time there has been a need for security administrators who don't necessarily have background knowledge in computer science. We have solved this problem by designing a new minor in this area. 
The organization of the courses makes it possible to increase the amount of foreign students and also offer some courses to other universities on a distant learning bases.

There are still some missing parts in this process. It is impossible to design very many new courses in a short time. Most of the new courses will first be tested using special courses with varying topics.

\section{REFERENCES}

[hut] http://www.hut.fi/English/

[master] http://www.tct.hut.fi/masters/

[S-72.244] http://www.comlab.hut.fi/opetus/244/

[T-110.300] http://www.tml.hut.fi/Studies/T-110.300/

[T-110.350] http://www.tml.hut.fi/Studies/T-110.350/

[T-110.400] http://www.tml.hut.fi/Studies/T-110.400/

[T-61.140] http://www.cis.hut.fi/Opinnot/T-61.140/index_en.shtml

[T-79.179] http://www.tcs.hut.fi/Teaching/T-79.179/

[T-76.115] http://mordor.soberit.hut.fi/T-76.115/

[T-76.601] http://mordor.soberit.hut.fi/T-76.601/

[T-110.501] http://www.tml.hut.fi/Studies/T-110.501/

[T-110.531] http://www.tml.hut.fi/Studies/T-110.531/

[T-110.401] http://www.tml.hut.fi/Studies/T-110.401/

[T-1 10.452] http://www.tml.hut.fi/Studies/T-110.452/

[T-1 10.454] http://www.tml.hut.fi/Studies/T-110.454/

[T-110.503] http://www.tml.hut.fi/Studies/T-110.503/

[T-110.554] http://www.tml.hut.fi/Studies/T-110.554/

[T-79.159] http://www.tcs.hut.fi/Teaching/T-79.159/

[T-79.232] http://www.tcs.hut.fi/Teaching/T-79.232/

[T-121.600] http://www.cs.hut.fi/Opinnot/T-121.600/ (in Finnish)

[katsikas]S. Katsikas, "Academic curricula and Curricula developments in Europe - the ERASMUS/SOCRATES Approach", proc. of IFIP TC11.8 First World Conference on Information Security Education, DSV, ISBN 91-7153-910-7, Sweden, 1999

[katsikas2] S. Katsikas, "A Postgraduate Programme on Information and Communication Systems Security", proc of IFIP TC11 int. conf. of information security, Kluwer Academic Publishers, ISBN 0-7923-7914-4, USA, 2000

[schou] C. Schou, "Information Security: International Curriculum Projects", proc. of IFIP TC11.8 Second World Conference on Information Security Education, Edith Cowan University, ISBN 0-7298-0498-4, Australia, 2001

[tik] http://www.hut.fi/Yksikot/Tieto/uusinde.htm

[tml] http://www.tml.hut.fi/english.html

[virtanen] T. Virtanen, "The Security Model to Combine the Corporate and Information Security", proc of IFIP TC11 int. conf. of information security, Kluwer Academic Publishers, ISBN 0-7923-7389-8, USA, 2001

[virtanen2] T. Virtanen, "Security Education in Finland", proc of $5^{\text {th }}$ Australian Security Research Symposium, ISBN 0-7298-0497-06, Edith Cowan University, Australia, 2001 